\title{
Perception and the External World
}

\author{
Declan Smithies
}

This paper begins from the assumption that perception plays an epistemic role in justifying beliefs about the external world. The aim of the paper is to explain how perception succeeds in playing this epistemic role. What is it about perception in virtue of which it justifies beliefs about the external world?

The debate between internalism and externalism in the epistemology of perception can be defined in many different ways, but one key point of contention is the epistemic role of phenomenal character. This is my main focus here. So for the purposes of this paper, internalism is the thesis that perception justifies belief solely in virtue of its phenomenal character, while externalism is the thesis that perception justifies belief at least partly in virtue of externalist facts about perception that are distinct from its phenomenal character. Proponents of internalism and externalism, so defined, can agree that perception justifies beliefs about the external world, but they disagree about how it does so.

This paper represents something of a change in view. Although I have defended internalism in previous work, this paper makes a modest concession to externalism. ${ }^{1}$ At the same time, my goal is argue that externalism can depart from the letter of internalism while retaining much of its spirit. To this end, I propose a moderate version of externalism on which externalist facts play a justifying role, but only insofar as they impact on the representational content of perception. This is to be contrasted with more radical versions of externalism on which externalist facts about perception play a justifying role that need not be reflected in its representational content. The main goal of the paper is to explain why a modest concession to externalism need not open the floodgates to more radical versions of

\footnotetext{
${ }^{1}$ In Smithies 2006 and 2014, I defend an internalist theory on which justification depends upon phenomenal character alone. To avoid false advertising, I should note that the proposal defended in this paper qualifies as internalism by many familiar definitions, including mentalism and access internalism.
} 
externalism. More specifically, I argue that epistemic level-bridging principles provide a principled rationale for keeping the floodgates closed.

The first four sections of the paper examine the connection between the phenomenal character of perception and its justifying role. Section one argues that phenomenal character is a necessary condition for perception to justify belief. Section two argues that phenomenal character is a difference-maker for perceptual justification in the sense that any difference in the phenomenal character of perception makes for some corresponding difference in its justifying role. Section three argues that phenomenal character is not the only difference-maker for perceptual justification, since its justifying role can differ with no corresponding difference in its phenomenal character. Section four presents a moderate version of externalism on which phenomenal character is fundamental even if it is not the only factor in determining the justifying role of perception.

The last two sections of the paper address a challenge for this view. The challenge is to make the case that this moderate version of externalism is a stable compromise between internalism on the one hand and more radical versions of externalism on the other. My response invokes epistemic level-bridging principles. Section five argues that epistemic level-bridging principles are in tension with radical versions of externalism, while section six argues that there is no such tension with moderate versions. I conclude that moderate externalism is a stable compromise that avoids the objections to internalism without compromising the motivations for rejecting radical externalism.

A few clarifications before I begin. First, this paper is exclusively concerned with the epistemic role of perception as a source of rational justification for beliefs about the external world as distinct from its role as a source of knowledge. ${ }^{2}$ Second, it is primarily concerned with justification in the forward-looking sense rather than the backward-looking sense - that is, the sense in which one has justification to hold

${ }^{2}$ I assume for now that knowledge is factive, while justification is non-factive. In section four, I argue against the view that justification is factive on the grounds that it conflicts with epistemic level-bridging principles. 
beliefs and other doxastic attitudes regardless of how or whether one holds them. ${ }^{3}$ Third, I want to bracket the justifying role of background beliefs in order to focus on the justifying role of perception itself. So, for these purposes, the justifying role of perception should be understood in terms of its role in providing defeasible and noninferential justification for beliefs about the external world. ${ }^{4}$

\section{The Phenomenal Condition}

Normal human perception has phenomenal character: it is conscious in the phenomenal sense that there is something it is like for the subject to perceive the external world. ${ }^{5}$ But perception does not need phenomenal character in order to represent the external world. In blindsight, for example, there can be representation and processing of perceptual information about stimuli in the subject's blind field that has no phenomenal character at all. ${ }^{6}$ This explains why subjects with blindsight can perform reliably in forced choice tasks - for instance, identifying a letter as an ' $\mathrm{X}$ ' or an 'O' and categorizing a line as horizontal or vertical - even when the stimulus is presented in the subject's blind field.

Now the question arises whether perception must have phenomenal character in order to justify beliefs about the external world. Does unconscious perception in blindsight, for example, provide justification for beliefs about the external world? Intuitively, the answer is no: blindsight no more justifies beliefs about objects in the blind field than conscious sight justifies beliefs about objects

3 The distinction is standard, although the terminology varies. Compare Firth's 1978 distinction between propositional and doxastic senses of reasonableness and Goldman's 1979 distinction between ex ante and ex post senses of justification. ${ }^{4}$ I assume that perception provides justification that is non-inferential at least in the sense that it does not depend on empirical justification to believe anything else. But this is consistent with the view that perception provides justification that depends upon a priori or default justification to believe that perception is reliable.

${ }^{5}$ See Block 1997 for the distinction between the phenomenal sense and various functionally defined senses of consciousness, including access consciousness and metacognitive consciousness.

${ }^{6}$ See Weiskrantz 1997 for an overview of empirical work on blindsight. Patients with type-1 blindsight report no visual experience, whereas patients with type- 2 blindsight report some degraded visual experience, so we can focus on cases where visual experience is entirely lacking. 
outside the field of view. I propose that this intuitive datum is best explained by the following condition:

The Phenomenal Condition: perception justifies belief about the external world if and only if it has some phenomenal character.

The Phenomenal Condition explains the epistemic asymmetry between normal conscious perception and unconscious perception in blindsight. Anyone who rejects the Phenomenal Condition must either dispute the intuitive datum to be explained or explain it in some other way. Let us consider these options in turn.

The intuition that unconscious perception in blindsight does not justify belief can be supported with an argument of the following kind:

(1) If unconscious perception in blindsight provides justification for belief, then blindsighted subjects are less than fully justified insofar as they refrain from forming beliefs on the basis of unconscious perception.

(2) Blindsighted subjects do in fact refrain from forming beliefs on the basis of unconscious perception.

(3) But blindsighted subjects are fully justified in so refraining. Therefore,

(4) Unconscious perception in blindsight does not provide justification for belief.

The first premise is an instance of the more general principle that being justified in the epistemic domain is a matter of regulating one's beliefs in ways that are appropriately responsive to whatever one has justification to believe. The second premise is just an empirical observation that subjects with blindsight do not in fact form beliefs on the basis of unconscious perception, but tend instead to regard their reports under forced choice conditions as mere guesswork and to express surprise when informed of their reliability. The third premise reflects the fact that blindsight - just like ordinary blindness - is a deficit in perception, rather than cognition. It is not that these subjects have a cognitive deficit that disables them from responding appropriately to perceptual sources of justification. Rather, they are lacking these 
perceptual sources of justification in the first place. And so we arrive at the conclusion that unconscious perception in blindsight provides no justification for belief. This explains why blindsighted subjects are justified in refraining from forming beliefs on the basis of unconscious perception.

One objection to the argument exploits a loophole in the first premise. It is generally agreed that perception provides justification that is defeasible in the sense that it can be defeated by doubts about the reliability of perception. ${ }^{7}$ And so one might argue that unconscious perception in blindsight provides justification for belief that is defeated by the doubts that blindsighted subjects have about their own reliability. In this way, perhaps we can explain why blindsighted subjects resist forming beliefs about objects in the blind field without casting aspersions on their epistemic credentials.

This objection raises the question whether blindsighted subjects have justification to doubt their own reliability. If not, then their doubts do not absolve them from epistemic criticism, but merely reinforce those epistemic criticisms. So the objection relies on the assumption that their doubts are justified. But if so, then what justifies them? I'll revisit this question below, but my contention is that doubts about the reliability of blindsight are justified because unconscious perception does not reveal itself through introspection. Even if one knows that blindsight is reliable, there is always room for justified doubt about whether one has a reliable capacity for blindsight, since blindsight does not reveal itself upon reflection. In the context of epistemic level-bridging principles, this undermines the claim that unconscious perception in blindsight provides justification in the first place.

A more straightforward response is to defuse the objection by abstracting away from the doubts that blindsighted subjects often have about their own reliability. Of course, they can be convinced of their own reliability - for example, by learning the results of experimental testing. In that case, they acquire inductive justification to believe that their guesses are now likely to be true on the grounds that they were reliably true in the past. But this inductive justification does not have

${ }^{7}$ See McDowell 1982 for a dissenting view. 
its source in unconscious perception as distinct from empirically justified beliefs about their own reliability in the circumstances. In contrast, conscious perception provides non-inferential justification for belief that cannot be explained solely in terms of empirically justified beliefs about one's reliability in the circumstances. As I will explain below, the same is not plausibly true of blindsight.

Consider Block's (1997) hypothetical super-blindsighter who forms beliefs automatically and non-inferentially on the basis of unconscious perception in much the same way that normal subjects form beliefs on the basis of conscious perceptual experience. ${ }^{8}$ Does the super-blindsighter (we'll call her Susan) have justification to form beliefs about objects in the blind field on the basis of unconscious perception? Intuitively, she does not. Either Susan is justified by beliefs about her own reliability or she is merely reliable, but not justified. In either case, her unconscious perception does not provide a source of justification for belief.

The epistemic predicament of Susan the super-blindsighter is closely parallel to that of BonJour's clairvoyant, Norman:

Norman, under certain conditions which usually obtain, is a completely reliable clairvoyant with respect to certain kinds of subject matter. He possesses no evidence or reasons of any kind for or against the general possibility of such a cognitive power or for or against the thesis that he possesses it. One day Norman comes to believe that the President is in New York City, though he has no evidence either for or against this belief. In fact the belief is true and results from his clairvoyant power under circumstances in which it is completely reliable. (BonJour 1985: 41)

Intuitively, Norman has no justification to form beliefs about the location of the President on the basis of his reliable faculty of clairvoyance. By parity of reasoning, Susan has no justification to form beliefs about objects in the blind field on the basis

${ }^{8}$ One qualification: Block's super-blindsighter is "trained to prompt himself at will, guessing without being told to guess" (1997: 385). But we can stipulate instead that he forms beliefs spontaneously without any need for self-prompting. 
of her reliable faculty of unconscious perception. However, these intuitive reactions can be challenged and so it is worthwhile to consider how we might support them with further argument. ${ }^{9}$

The argument that I propose relies on an epistemic level-bridging principle:

Level Bridging: One has justification to believe that $p$ if and only if one has justification to believe that one has justification to believe that $p$.

It is important to be clear about what this principle says. It doesn't say that one's first-order beliefs are justified if and only if they are formed on the basis of justified higher-order beliefs about what one has justification to believe. It doesn't say that one's first-order beliefs are justified if and only if one has an infinite hierarchy of justified higher-order beliefs. It just says that one has first-order justification if and only if one has higher-order justification to believe that one has first-order justification. And here we are talking about undefeated, all things considered justification in the forward-looking sense. ${ }^{10}$

The argument from Level Bridging takes the following form. Bonjour stipulates that Norman has no evidence that justifies believing that he has a reliable faculty of clairvoyance. So presumably Norman lacks higher-order justification to believe that he has first-order justification to form beliefs on the basis of clairvoyance. Given Level Bridging, it follows that Norman lacks first-order justification to form beliefs on the basis of clairvoyance. Similarly, we can stipulate that Susan has no evidence that justifies believing that she has a reliable faculty of unconscious perception. Therefore, Susan lacks higher-order justification to believe that she has first-order justification to form beliefs on the basis of unconscious perception. And Level Bridging implies, once again, that Susan lacks first-order justification to form beliefs on the basis of unconscious perception.

\footnotetext{
${ }^{9}$ See Lyons 2009: Ch.5 for opposing verdicts about clairvoyance-style cases. 10 In Smithies 2012a, I use these points in defending the level-bridging principles against the charge of over-intellectualization and psychological regress problems. See also Smithies 2012c for my response to Williamson's anti-luminosity argument.
} 
One option is to block the argument by rejecting Level Bridging. On this view, Norman and Susan have first-order justification for their beliefs, but they do not have higher-order justification to believe that they have first-order justification. As I will explain, however, this view has some implausible consequences.

The first implausible consequence is that people sometimes have justification to believe Moorean conjunctions that intuitively no one has justification to believe. Let's suppose, just for the sake of the argument, that Susan has justification to believe that there is an $\mathrm{X}$ in her blind field, although she lacks justification to believe that she has justification. Which doxastic attitude does she have justification to adopt towards the proposition that she has justification to believe that there is an $\mathrm{X}$ in her blind field? If she lacks justification to believe it, then she must have justification either to disbelieve it or to withhold belief. But then she has justification to believe one of the following Moorean conjunctions:

(1) There is an X in my blind field, but I do not have justification to believe this.

(2) There is an X in my blind field, but it is an open question whether I have justification to believe this.

Intuitively, however, anyone who believes these Moorean conjunctions is thereby unjustified. And this is because no one has justification to believe them. ${ }^{11}$

The second implausible consequence is that people can have justification for beliefs that do not have what it takes to survive a fully justified process of critical reflection. Critical reflection is the activity of reflecting on which beliefs one has justification to hold and revising one's beliefs accordingly. The aim of the activity is to bring one's first-order beliefs into line with one's higher-order reflections about which beliefs one has justification to hold. Critical reflection is fully justified when one's first-order beliefs are brought into line with justified higher-order reflections.

${ }^{11}$ See Smithies 2012a for a more detailed version of this argument. Bergmann 2005 and Littlejohn 2013 argue (to put the point in my terminology) that justification for believing Moorean conjunctions is "finkish" in the sense that it is destroyed in process of believing them. See Smithies 2012a: 16-20 for my response. 
So when it is fully justified, critical reflection results in belief if and only if one has higher-order justification to believe that one has first-order justification for that belief. Susan's belief that there is an X in her blind field cannot survive a fully justified process of critical reflection, since she lacks higher-order justification to believe that she has first-order justification for that belief. But it is implausible to maintain that she has justification for beliefs that cannot survive a fully justified process of critical reflection. ${ }^{12}$

The only remaining option is to block the argument by insisting that Susan has not only first-order justification for her beliefs but also higher-order justification to believe that she has first-order justification. But it is hard to square this with our description of the examples. We stipulated that Susan has no evidence that justifies believing that she has a reliable faculty of unconscious perception. So her total evidence justifies doubting - that is, disbelieving or withholding belief - that she has any such reliable faculty of unconscious perception. But any body of evidence that justifies doubting the reliability of forming beliefs in a certain way also justifies doubting that one has justification to form beliefs in that way. And one cannot have justification to believe a proposition while also having justification to disbelieve it or to withhold belief. Therefore, it follows that Susan lacks higher-order justification to believe that she has first-order justification to form beliefs on the basis of unconscious perception.

As we have seen, Level Bridging provides argumentative support for the intuitive datum that the Phenomenal Condition is designed to explain: namely, the existence of an epistemic asymmetry between conscious perception and blindsight. But is the Phenomenal Condition needed for explaining this epistemic asymmetry or can we explain it in some other way? There are functional differences as well as phenomenal differences between conscious perception and blindsight. For instance, unconscious perceptual information in blindsight is not access conscious in the sense of being poised for spontaneous use in the control of action, reasoning, and verbal report. And so one might explain the epistemic asymmetry as follows:

${ }^{12}$ See Smithies 2015 for the proposal that justification is the epistemic property that makes a belief suited to survive a fully justified process of critical reflection. 
The Accessibility Condition: perception justifies belief about the external world if and only if it is access conscious.

But the original point of Block's super-blindsight case was to show that perceptual information could be access conscious without being phenomenally conscious. And yet, as I argued above, unconscious perception in super-blindsight does not justify beliefs about the external world.

One reaction is to impose a more demanding functional condition on perceptual justification. For instance, neither blindsight nor super-blindsight is metacognitively conscious in the sense that it is the target of higher-order thoughts that are formed directly on its basis without mediation by inference or observation. So we might seek to explain the epistemic asymmetry as follows:

The Metacognition Condition: perception justifies belief about the external world if and only if it is metacognitively conscious.

One problem is that this more demanding condition is not necessary for perceptual justification, since children and animals can have beliefs about the external world that are justified by perception without having beliefs about their own perception. Another problem is that it is not sufficient. Consider the hyper-blindsighter who forms beliefs of two kinds on the basis of unconscious perception: beliefs about the external world and beliefs about their own internal states. Intuitively, the latter are no more justified than the former. If reliability is not sufficient to justify beliefs about the external world, then why should it be sufficient to justify beliefs about the internal world? But we cannot turn unjustified beliefs into justified beliefs by adding more unjustified beliefs.

These examples make it plausible that unconscious perception cannot provide justification for belief however much we elaborate its functional role. If this is right, then functional asymmetries between conscious sight and blindsight cannot 
explain the epistemic asymmetry between them. The Phenomenal Condition is therefore indispensable for explaining this epistemic asymmetry.

The Phenomenal Condition can be further motivated by its role in explaining Level Bridging. Perception must have phenomenal character in order to provide first-order justification for beliefs about the external world in such a way as to guarantee that one also has higher-order justification. Unconscious perception does not reveal itself through introspection and so one can have unconscious perception without thereby having justification to believe that one does. That is why subjects with blindsight are typically justified in doubting their own reliability, since they lack justification to believe that they have are unconsciously representing and processing perceptual information. Conscious experience, on the other hand, reveals itself through introspection in the sense that one cannot have conscious experience without thereby having introspection justification to believe that one does. This guarantees that the source of one's justification for beliefs about the external world is always accessible through introspection and reflection alone. ${ }^{13}$

\section{Phenomenal Grounding}

I argued in section one that that phenomenal character is a necessary condition for perception to play its justifying role. But it is a further question whether perception justifies belief in virtue of its phenomenal character. What is the nature of the connection between the phenomenal character of perceptual experience and its justifying role? I want to begin by distinguishing the following pair of claims:

Phenomenal Grounding: any difference in the phenomenal character of perceptual experience grounds some difference in its justifying role.

Phenomenal Dependence: any difference in the justifying role of perceptual experience depends upon some difference in its phenomenal character.

\footnotetext{
${ }^{13}$ See Smithies 2012b for a more extended discussion of the relationship between consciousness and introspection in the context of a defence of internalism.
} 
Phenomenal Grounding is the thesis that the phenomenal character of perceptual experience is a difference-maker for perceptual justification, whereas Phenomenal Dependence is the distinct thesis that it is the only difference-maker. In this paper, I argue for Phenomenal Grounding and against Phenomenal Dependence. This is a change in my views, since I endorsed Phenomenal Dependence in previous work. My argument for Phenomenal Grounding is that it follows from two plausible and widely held assumptions. The first assumption is Representationalism:

Representationalism: the phenomenal character of perceptual experience is identical with a certain kind of representational content.

Representationalism implies that there is a kind of representational content that is identical with phenomenal character. Call this phenomenal content. But it does not imply that all representational content is phenomenal content. Therefore, Representationalism is consistent with the assumption that unconscious perception in blindsight represents the external world. It merely implies that there is a kind of representational content - namely, phenomenal content - that requires phenomenal consciousness.

There is a vast literature on Representationalism, and I cannot do justice to it here, but I will briefly sketch one compelling source of motivation for the view. Consider the opposing view that the phenomenal character of perceptual experience is entirely independent of its representational content. This seems quite wrong. One cannot coherently imagine someone whose perceptual experience has the very same phenomenal character as one's own but none of the same representational content. And this is because perceptual experience has representational content that is intrinsic to its phenomenal character. For instance, it is intrinsic to the phenomenal character of the visual experience that I am now having that it represents that there is a mug of brown liquid on the table to the left. No one could have an experience with just the same phenomenal character without thereby representing that there is a mug of brown liquid on the table to the left. The simplest 
and best explanation of this fact is that the phenomenal character of perceptual experience just is a certain kind of representational content. ${ }^{14}$

The second assumption in the argument is the Content Principle:

The Content Principle: one has defeasible, non-inferential justification to believe that $p$ on the basis of perceptual experience if and only if one has a perceptual experience with the representational content that $p .{ }^{15}$

The Content Principle captures the way in which the representational content of perceptual experience is relevant to its justifying role. Consider an analogy with testimony. What you're justified in believing on the basis of testimony depends upon the content of the testimony that you receive - that is, it depends on what people tell you (or, perhaps better, on what they seem to be telling you). Similarly, what you're justified in believing on the basis of perceptual experience depends upon its content - that is, it depends on what perceptual experience tells you.

The Content Principle is not universally accepted: radical versions of externalism claim that perception justifies belief in virtue of externalist facts that need not impact on its representational content. I argue against these views in section five, but for now, I take the Content Principle as a plausible starting point. ${ }^{16}$

The Content Principle is stated as a biconditional, but if the right hand side is understood to have explanatory priority, then it implies the following pair of claims:

\footnotetext{
${ }^{14}$ See McGinn 1988, Siewert 1998, Horgan and Tienson 2002, and Chalmers 2004 for related arguments. See also Harman 1990, Tye 1995, and Byrne 2001 for arguments from transparency. Peacocke 1983 and Block 2003 raise objections that have been widely discussed elsewhere.

${ }^{15}$ See Pryor's 2000 defence of dogmatism and Huemer's 2001: Ch. 5 defence of phenomenal conservatism for related principles.

${ }^{16}$ Silins 2011 raises objections to the Content Principle that I don't have space to discuss here, including a version of the problem of the speckled hen. See Smithies 2012c: 729-31 for some relevant discussion.
} 
Representational Grounding: any difference in the representational content of perceptual experience grounds some corresponding difference in its justifying role.

Representational Dependence: any difference in the justifying role of perceptual experience depends upon some corresponding difference in its representational content.

Phenomenal Grounding follows from the combination of Representationalism together with Representational Grounding. If phenomenal character is a kind of representational content, and if representational content is a justificational difference-maker, then so is phenomenal character. As I will explain, however, Phenomenal Dependence cannot be motivated in the same way, since it does not follow from Representationalism together with Representational Dependence.

Representationalism implies that perceptual experience has a certain kind of representational content - namely, phenomenal content - that is identical with its phenomenal character. But it is consistent with the further claim that perceptual experience also has a different kind of representational content - namely, externalist content - that is distinct from and fails to supervene upon its phenomenal character. For instance, it is consistent with the view that perceptual experiences with the same phenomenal character can represent different externalist contents in virtue of standing in different perceptual relations to the external world.

In section four, I argue that perceptual experience has two levels of representational content - that is, phenomenal content and externalist content. ${ }^{17}$ Suppose for the sake of argument that this two-level theory is correct. The Content Principle is not restricted to any particular kind of representational content: it applies to both phenomenal and externalist contents of perceptual experience. The upshot is that phenomenal character is not uniquely suited to play an epistemic role in grounding differences in perceptual justification, since there are externalist facts

17 Two-level theories of the representational content of perceptual experience are defended by Horgan and Tienson 2002, Chalmers 2004, and Siegel 2011: Ch. 6. 
about perception that also play a difference-making role. I develop this argument against Phenomenal Dependence in section three below.

\section{Against Phenomenal Dependence}

The argument against Phenomenal Dependence is that relational facts about which objects one perceives play a role in determining one's justification to believe de re propositions about objects. We can therefore generate counterexamples to Phenomenal Dependence in which phenomenal duplicates perceive distinct objects and thereby differ in which de re propositions they have justification to believe. This is just one instance of a more general phenomenon of believing externalist contents, but it is a good test case to focus on.

A de re proposition is a proposition about an object that no subject can believe unless the object exists and stands in an appropriate relation - such as a perceptual relation - to the subject. ${ }^{18}$ Someone who hallucinates a rotten apple may come to believe the general proposition that there is a rotten apple in their environment, but they cannot believe de re propositions about any particular apple to the effect that it is rotten, since there is no such apple that they perceive. ${ }^{19}$ Similarly, someone who perceives a rotten apple can believe de re propositions about that particular apple, but they cannot believe de re propositions about numerically distinct but qualitatively identical apples that they do not perceive.

Here is an example from Davies that illustrates the point:

If I look at an apple, Fido, and think, 'That apple is rotten', and you look at a numerically distinct but qualitatively indistinguishable apple, Fifi, and think,

'That apple is rotten', then - be we ever so similar internally - our beliefs

${ }^{18} \mathrm{~A}$ proposition is de re (or object-dependent) with respect to an object only if it is true of that object in in every possible world in which it exists. See Evans 1982: Ch.6, Martin 2002, and Siegel 2011: Ch.6. In this paper, I focus on de re belief that is based on perception, but I don't rule out the possibility of de re belief that is based on memory, testimony, or inference.

${ }^{19}$ Johnston points out that "although we can hallucinate real things and real people, no such hallucination can provide an original source of de re thought about those particular things or people" (2004: 129). 
have different contents in virtue of our being related to different apples. My belief, concerning Fido, to the effect that it is rotten, is a belief whose correctness depends upon how things are with Fido: whether Fido is indeed a rotten apple. Your belief, in contrast, is one whose correctness is indifferent to how things are with Fido, but depends instead upon how things are with Fifi. In that sense, the contents of our beliefs are object-involving. (Davies 1997: 313-4)

We can stipulate that you and I are intrinsic duplicates who stand in different relations to the external world. I am looking at Fido while you are looking at a numerically distinct but qualitatively identical object, Fifi. Because we are intrinsic duplicates, it is prima facie plausible that we have visual experiences with the same phenomenal character. Each of us believes the general proposition that there is a rotten apple in our environment. In addition, each of us believes a de re proposition about the apple in our own environment to the effect that it is rotten. I believe a de re proposition about Fido, whereas you believe a de re proposition about Fifi, and not vice versa. Moreover, we can assume that each of us is fully rational and hence that we believe all and only those propositions that we have justification to believe. The upshot is that we are phenomenal duplicates, but we do not have justification to believe all the same propositions. This contradicts Phenomenal Dependence.

The argument can be summarized as follows:

(1) You and I are phenomenal duplicates who see distinct objects.

(2) I believe the de re proposition that Fido is rotten, whereas you believe the de re proposition that Fifi is rotten, and not vice versa.

(3) You and I are fully rational so each of us believes every proposition that we have justification to believe on the basis of perceptual experience.

(4) Therefore, Phenomenal Dependence is false: you and I are phenomenal duplicates but we have justification to believe different propositions on the basis of perceptual experience. 
I will consider and reject three strategies for blocking the argument in this section before considering the implications of accepting its conclusion in the next section.

The first option is to reject the first premise by denying that all intrinsic duplicates are phenomenal duplicates. On the relational view of experience, the phenomenal character of experience in a case of veridical perception consists in the perceptual relation that holds between the subject and the external world. ${ }^{20}$ On this view, the phenomenal character of experience depends not just on intrinsic properties of the subject but on extrinsic relations to objects in the external world in particular, it depends on which objects the subject perceives. Intrinsic duplicates can differ in their phenomenal character if they are perceptually related to distinct objects (or none at all). Moreover, the resulting differences in the phenomenal character of their experience can explain the relevant differences in which de re propositions they have justification to believe.

One problem for the relational view of experience is to explain how the transition from perceiving to hallucinating or from perceiving one object to perceiving another can be "experientially seamless" in the sense that it cannot be detected through introspection. As Johnston (2004: 122) puts the point, "Try as you might, you would not notice any difference, however closely you attend to your visual experience." The standard explanation is that the transition is seamless because the phenomenal character of experience remains constant throughout. But proponents of the relational view insist that its phenomenal character changes in ways that you're unable to detect. On this view, perceptions of distinct objects and hallucinations can share the negative epistemic property of being indiscriminable from veridical perception of a particular object by reflection alone. But they need not share phenomenal character in a more fundamental sense that explains why they share this negative epistemic property. For instance, Martin (2004) proposes an epistemic conception of hallucination on which there is no more fundamental

20 This view is sometimes called "naïve realism". Proponents include Campbell 2002, Martin 2004, Brewer 2006, and Fish 2008. One can deny that phenomenal character is intrinsic without endorsing the relational view of experience, but this would not be sufficient to block the argument. 
property in virtue of which a perfect hallucination is indiscriminable by reflection from a corresponding veridical perception. ${ }^{21}$

The epistemic conception of hallucination faces some compelling objections. For instance, Siegel (2004) observes that two experiences that differ in their phenomenal character may nevertheless be indiscriminable by reflection because the subject is inattentive or delusional or incapable of reflecting on her experiences. Martin's (2004) reply is that a perfect hallucination is indiscriminable from a corresponding veridical perception in an impersonal sense that abstracts away from the limitations of the subject's cognitive capacities. It is natural to understand this proposal in counterfactual terms: even if the subject's cognitive capacities were idealized in the relevant ways, the subject would be unable to discriminate a perfect hallucination from a corresponding veridical perception by reflection alone. But it is difficult to evaluate the truth of this counterfactual without holding fixed the phenomenal character of the subject's experience. The epistemic conception of hallucination is forced to take the relevant epistemic facts about impersonal indiscriminability as ungrounded primitives. The standard view is superior insofar as it explains the relevant epistemic facts about impersonal indiscriminability in terms of shared phenomenal character, rather than simply taking them as primitive.

The second option is to reject the second premise of the argument by denying that subjects who perceive distinct objects also believe distinct de re propositions about those objects. In the example above, both you and I believe the general proposition that there is a rotten apple in our environment. One and the same proposition is made true by distinct apples in our respective environments. What is denied is that each of us believes a de re proposition about the apple in our own environment. More generally, on this view, the representational content of perceptual experience and belief is exclusively phenomenal content that supervenes

${ }^{21}$ Martin 2002 allows that perceptions of numerically distinct but qualitatively identical objects can share a general phenomenal character while differing in their particular phenomenal nature. 
upon the phenomenal character of the subject. Farkas (2008) calls this view "phenomenal intentionality without compromise".22

Many philosophers believe that some representational content of belief is externalist content that depends not just on the intrinsic phenomenal character of the subject but also on the subject's extrinsic relations to the environment. But is there any compelling reason to believe this? Many are persuaded by twin-earth examples in which phenomenal duplicates are embedded in different environments. ${ }^{23}$ But intuitions about cases will take us only so far in the face of theoretical opposition. We need to ask whether there is any theoretical role for externalist content that cannot be played by phenomenal content alone.

One important proposal is that externalist content plays an essential role in explaining relational facts about my behavior. The general idea is that relational facts about my behavior need to be explained in terms of relational facts about my mental states. For instance, my de re belief about Fido to the effect that it is rotten explains why I pick it up and throw it in the trash. Opponents of externalist content claim that my behavior is explained by the general belief that there is a rotten apple in my environment together with the environmental fact that Fido is in fact the rotten apple in my environment. Arguably, however, we cannot preserve the explanatory power of relational facts about my mental states simply by conjoining intrinsic facts about my mental states with relational facts about my environment. ${ }^{24}$

The final option is to reject the third premise by denying that full rationality requires believing all propositions that one has justification to believe. This is the option that I endorsed in previous work, although I now reject it for reasons that I

\footnotetext{
${ }^{22}$ Farkas does not deny that there are semantic differences between singular terms and definite descriptions, but on her view, these semantic differences concern reference rather than content. The view is that content determines reference only relative to a context and the way in which reference is determined depends on the phenomenal character of experience.

${ }^{23}$ See Strawson 1959, Putnam 1975 and Burge 1979 for examples of this kind.

${ }^{24}$ Peacocke 1993, Yablo 1997, and Williamson 2000: Ch.3 develop this argument in more detail than I have space for here.
} 
will explain below. ${ }^{25}$ On this view, one's perceptual relations to the external world constrain which propositions one is able to believe, but not which propositions one has justification to believe. Thus, phenomenal duplicates have justification to believe the very same propositions, although they differ in which justified beliefs they are able to hold. So, for example, I have justification to believe de re propositions about Fifi as well as Fido, but I cannot use it in forming justified beliefs about Fifi because I don't stand in the right kind of perceptual relation to Fifi.

Williamson (2007) argues against a related proposal made by Audi (2001) on the grounds that it has the implausible consequence that one's epistemic situation is always misleading. After all, it implies that I have justification to believe many false propositions, including the de re proposition that Fifi is within reach. In response, however, it is not clear that having justification to believe false propositions is sufficient for one's epistemic situation to be misleading unless one is in danger of believing them. But in this case, I am in no danger of believing the false de re proposition that Fifi is within reach since I don't stand in the right kind of perceptual relation to Fifi.

Another consequence (noted by Nico Silins) is that I have justification to believe inconsistent propositions - for instance, the de re proposition that Fido is the only apple within reach and the de re proposition that Fifi is the only apple that within reach. But this consequence is not intolerable. One of the lessons of Kripke's (1979) puzzle about belief is that one can have justification to believe inconsistent propositions so long as one lacks justification to believe that they are inconsistent. For example, Pierre believes that London is pretty and also believes that London is not pretty, but he is not thereby unjustified because he believes these propositions under different modes of presentation and so he lacks justification to believe that they are inconsistent. Similarly, if someone switches Fido and Fifi without my noticing, then I will believe inconsistent de re propositions about Fido and Fifi, but I

25 See Smithies 2006: 27-8 and 2014: 112. I am grateful to Nico Silins and Alex Byrne for conversations that eventually led me to change my mind on this issue. 
am not thereby unjustified because I believe them under the same (or similar) mode of presentation and so I lack justification to believe that they are inconsistent. ${ }^{26}$

In my view, the main problem with the third option is that it is inconsistent with an attractive principle linking forward-looking and backward-looking senses of rationality or justification in the epistemic domain:

The Linking Principle: if one is fully rational or justified in the backwardlooking sense, then one believes that $p$ if and only if one has sufficient reason or justification in the forward-looking sense to believe that $p .{ }^{27}$

In the practical domain, one may have sufficient justification for incompatible courses of action - as in the case of Buridan's ass - but rationality does not require taking all of them, since any one will do. But in the epistemic domain, it is much less plausible that one can have sufficient justification for conflicting doxastic attitudes. ${ }^{28}$ The Linking Principle is incompatible with the claim that I have justification for believing de re propositions about Fifi, since my rationality is in no way impugned by the fact that I do not stand in the right kind of perceptual relations to entertain de re propositions about Fifi.

I therefore conclude that Phenomenal Dependence is false. Phenomenal duplicates can differ in which de re propositions about objects they have defeasible and non-inferential justification to believe on the basis of perceptual experience owing to differences in their perceptual relations to the external world. In the next

\footnotetext{
${ }^{26}$ Another way to make essentially the point is that the externalist contents of these beliefs are inconsistent, but the phenomenal modes of presentation are consistent. See Chalmers 2002 for this diagnosis of Kripke's puzzle.

27 The principle needs a qualification to deal with finkish cases in which believing a proposition destroys one's justification, including Moorean conjunctions of the form, ' $p$ and I don't believe that $p$ '. But adding this qualification doesn't solve the problem that I am raising here.

${ }^{28}$ The debate in epistemology between uniqueness and permissiveness is relevant here. See the exchange between White 2013 and Kelly 2013 for further discussion. All I need here is intrapersonal (as distinct from interpersonal) uniqueness.
} 
section, I consider the consequences of this conclusion for the debate between internalism and externalism in the epistemology of perception.

\section{Moderate versus Radical Externalism}

One dimension of the debate between internalism and externalism in the epistemology of perception concerns the epistemic role of externalist facts defined as facts about perception that are distinct from its phenomenal character. Internalism is defined here as the view that perception justifies belief solely in virtue of its phenomenal character, while Externalism is defined as the view that perception justifies belief at least in part in virtue of externalist facts.

Externalism can be further subdivided into moderate and radical versions. Moderate Externalism can be defined as the view that externalist facts impact on the justificatory role of perception only by virtue of their impact on its representational content, while Radical Externalism denies this. Moderate and Radical Externalism therefore disagree about whether the Content Principle is true.

The argument against Phenomenal Dependence in section three establishes that Externalism is true and that Internalism is false: externalist facts about one's perceptual relations to the external world impact on which de re propositions about objects one has defeasible, non-inferential justification to believe on the basis of perceptual experience. My goal in this section is to argue that this concession is consistent with Moderate Externalism and so does not force the acceptance of Radical Externalism. In sections five and six below, I argue that this is a stable and well-motivated compromise.

The version of Moderate Externalism that I propose relies upon a two-level theory of representational content. Representationalism entails that perceptual experience has phenomenal content - that is, it has some representational content that is identical with its phenomenal character. But I also maintain that perceptual experience has externalist content - that is, it is has some representational content that is distinct from and does not supervene upon its phenomenal character, but varies depending upon its relations to the external world. 
Here is a simple argument for this claim based on the example from Davies that we discussed in section three:

(1) You and I are phenomenal duplicates who see distinct objects.

(2) My perceptual experience represents the de re proposition that Fido is rotten, whereas your perceptual experience represents the de re proposition that Fifi is rotten, and not vice versa.

(3) Therefore, our perceptual experiences have externalist contents that are distinct from and do not supervene upon their phenomenal character.

It is worth noting that Davies explicitly rejects the second premise of this argument. He argues that the representational content of perceptual experience is existentially quantified content, rather than object-involving content, precisely on the grounds that it supervenes upon phenomenal character alone:

The perceptual content of experience is a phenomenological notion: perceptual content is a matter of how the world seems to the experiencer. If perceptual content is, in this sense, 'phenomenological content' then, where there is no phenomenological difference for the subject, there is no difference in perceptual content. So if two objects are genuinely indistinguishable for a subject, then a perceptual experience of the one has the same content as a perceptual experience of the other. (Davies 1997: 314)

But we can accept that perceptual experience has phenomenal content without accepting that its representational content is exhausted by its phenomenal content. As far as I can see, there is no good reason to accept this further claim. Moreover, epistemological and explanatory considerations provide some good to reject it.

If we follow Davies in assuming that belief represents de re propositions, then it is hard to resist the conclusion that perceptual experience does too. After all, we are sometimes justified in believing de re propositions on the basis of perceptual experience, but it is not clear how perceptual experience can play this justifying role 
unless it represents those de re propositions. Why is it that my experience provide me with justification to believe de re propositions about Fido, while your experience provides you with justification to believe de re propositions about Fifi, and not vice versa? The most plausible answer is that my experience represents de re propositions about Fido, while your experience represents de re propositions about Fifi, and not vice versa.

We can also give an explanatory argument for the same conclusion. Compare the explanatory argument we considered in section three for the conclusion that belief represents de re propositions. The argument was that relational facts about my behavior need to be explained in terms of relational facts about my beliefs: for instance, my de re belief about Fido to the effect that it is rotten explains why I pick it up and throw it in the trash. By the same token, relational facts about my beliefs need to be explained in terms of relational facts about perception: for instance, I believe the de re content that Fido is rotten because my perceptual experience represents that Fido is rotten. An opponent might claim that the explanatory work can be done by conjoining the fact that perceptual experience represents the general proposition that there is a rotten apple before me with the relational fact that Fido is the rotten apple before me. But this faces the same objection as before: it is not clear that we can preserve the explanatory power of relational facts about mental states by conjoining intrinsic facts about mental states with relational facts about the environment. So, there is no principled motivation for the view that de re propositions are represented in cognition but not perception.

I conclude that perceptual experience represents both phenomenal and externalist contents. But the externalist contents of perceptual experience are not wholly independent of its phenomenal contents. On the contrary, its externalist contents are indirect contents in the sense that Silins defines below: 
A content that $p$ of an experience is indirect if the experience has the content that $p$, and has the content that $p$ at least in part in virtue of having some other content that $q \cdot{ }^{29}$ (Silins 2011: 354)

Perceptual experience represents externalist contents in virtue of representing phenomenal contents in a specific environment. The phenomenal contents of perceptual experience impose substantial constraints on how its externalist contents are determined: they are determined in a way that depends on whether, and if so, how the external environment satisfies these constraints. ${ }^{30}$ On this view, externalist content is partially grounded in phenomenal character. But there is no commitment to the further claim that externalist content is factorizable in the sense that it can be given a conjunctive analysis in terms of phenomenal content together with relations to the external environment. ${ }^{31}$

We can now explain an epistemic asymmetry between the externalist contents of perceptual experience and the externalist contents of unconscious perception in blindsight. What explains why the former and not the latter are justificational difference-makers? The answer is that the externalist contents of perceptual experience are partially grounded in phenomenal character, whereas the externalist contents of unconscious perception in blindsight are not. The upshot is that the phenomenal character of perceptual experience has a fundamental role to play in justifying beliefs about the external world even if it is not the sole factor that makes for justificational differences.

On the view that I am proposing, perceptual experience provides justification to believe phenomenal contents solely in virtue of its phenomenal character, but it also provides justification to believe externalist contents in virtue of its phenomenal

\footnotetext{
${ }^{29}$ Silins rejects the Content Principle, but he endorses a related thesis of Content Mediation: "When an experience has the indirect content that $P$, an experience can immediately justify you in believing that $P$ even if it is not a phenomenal content of experience." (2011: 355)

30 These constraints are called "grounding presuppositions" in Horgan and Tienson 2002 and "conditions on extension" in Chalmers 2004.

${ }^{31}$ See Williamson 2000: Chs. 1-3 for arguments against factorizability.
} 
character together with its relations to the external world. Thus, externalist facts make an epistemic impact on the justificatory role of perceptual experience but only insofar as they bear on its representational content. They make no independent epistemic contribution of the kind that Radical Externalism claims. ${ }^{32}$

The resulting view is a version of Moderate Externalism that is consistent with the Content Principle and so makes room for rejecting Internalism without embracing Radical Externalism. But is there any principled rationale for this compromise view? What is the motivation for allowing externalist facts to make an epistemic impact on perceptual justification for belief but only by way of their impact on the representational content of perception? In the next two sections, I address this challenge by invoking the epistemic level-bridging principle that was introduced in section one. I argue in section five that Level Bridging is in tension with Radical Externalism and in section six that there is no such tension with Moderate Externalism.

\section{Against Radical Externalism}

Radical Externalism comes in many different forms, including the following:

Reliabilism: a perceptual experience with the representational content that $p$ provides justification to believe that $p$ only if it reliably indicates that $p .{ }^{33}$

Factivism: a perceptual experience with the representational content that $p$ provides justification to believe that $p$ only if one perceives that $p$, where this entails that it is a fact that $p$ and (on some versions) that one knows or one is in a position to know that $p .^{34}$

\footnotetext{
32 See also Conee and Feldman 2004: 82 for a version of Moderate Externalism. Conee 2007 calls the view "externally enhanced internalism".

33 Proponents of Reliabilism include Goldman 1979, Sosa 1991, Burge 2003, Bergmann 2006 and Lyons 2009. These authors disagree about the kind of reliability that is necessary for justification.

34 Proponents of Factivism include McDowell 1995, Williamson 2007, Roessler 2009, Littlejohn 2012, Pritchard 2012, and Schellenberg 2013, this volume.
} 
Etiologism: a perceptual experience with the representational content that $p$ provides justification to believe that $p$ only if does not have a bad etiology, including certain kinds of cognitive penetration. ${ }^{35}$

What these versions of Radical Externalism have in common is that they accept one direction of the Content Principle while rejecting the other. ${ }^{36}$ On these views, the fact that a perceptual experience represents that $p$ is necessary but not sufficient for it to provide defeasible, non-inferential justification to believe that $p$. In addition, further external conditions must be satisfied.

Different versions of Radical Externalism impose different external conditions on the so-called "good case" in which one has justification to believe that $p$ on the basis of a perceptual experience that represents that $p$. What all versions of Radical Externalism have in common is that there is some epistemic disparity between the good case and the bad case. On simple versions, one has justification for belief in the good case but not in the bad case. On more complex versions, one has justification for belief in both good and bad cases, but one has justification to believe with a higher degree of confidence in the good case than the bad case. ${ }^{37}$ Either way, there is some belief or other doxastic attitude that one has justification to adopt in the good case but not the bad case. In order to simplify the discussion, I'll ignore this complication in what follows.

Here is a general form of argument against Radical Externalism:

\footnotetext{
35 Proponents of Etiologism include Siegel 2011 and McGrath 2013.

${ }^{36}$ Some versions of Radical Externalism reject both directions of the Content Principle, but I will focus on less radical versions of Radical Externalism, since my arguments will extend to more radical versions too.

37 Williamson 2007 holds that one has some degree of justification in the bad case, but more justification in the good case. Schellenberg's 2013 distinction between phenomenal evidence and factive evidence has the same effect; see Schellenberg, this volume for further discussion.
} 
(1) If perceptual experience does not provide equal justification for belief in the good case and the bad case, then subjects in the bad case are less than fully justified insofar as they form the same beliefs as subjects in the good case.

(2) Subjects in the bad case form the same beliefs as subjects in the good case.

(3) Subjects in the bad case are fully justified. Therefore,

(4) Perceptual experience provides equal justification for belief in the good case and the bad case.

This argument makes explicit the reasoning that lies behind Cohen's (1984) "new evil demon" problem for Reliabilism. Consider a phenomenal duplicate of mine who is a victim of an evil demon that deceives him about the external world. My phenomenal duplicate holds many (if not all) of the same beliefs that I do and seems to be no less justified than I am in holding those beliefs. The upshot is that my perceptual experience provides equal justification for belief regardless of whether or not it is a reliable guide to the external world.

Cases of perceptual illusion and hallucination raise similar problems for Factivism. Suppose that Macbeth undergoes a "seamless transition" from the good case of perceiving that there is a dagger before him to the bad case of merely hallucinating that there is a dagger before him. The transition is "seamless" in the sense that Macbeth cannot know by introspection that the transition is occurring and it makes no relevant impact on his doxastic attitudes - in particular, he continues to believe that there is dagger before him with the same high level of confidence. Factivism makes the implausible prediction that Macbeth is unjustified since he does not have justification for the same doxastic attitude in the good case and the bad case alike. And we can raise the same problem for Etiologism by considering seamless transitions between good and bad etiologies.

Proponents of Radical Externalism sometimes reply to this objection by drawing a distinction between justification and blamelessness. The suggestion is that in the bad case one does not have justification for one's beliefs, but one nevertheless has a good excuse for holding them - namely, that one is in a case that is indiscriminable by reflection from the good case. Since one has such an excuse, 
one cannot be blamed for forming these beliefs, but it does not follow that one has justification for those beliefs. In the bad case, one is blameless, but unjustified. ${ }^{38}$

Everyone should agree that blameless is not sufficient for justification. This is best illustrated by examples in which victims of brainwashing, drugs or mental illness form unjustified beliefs through no fault of their own. Consider, for example, a patient with Capgras delusion who believes that his wife has been replaced by an imposter. The belief is clearly unjustified but we do not blame the patient because he is delusional. Nevertheless, it seems quite wrong to assimilate cases of perceptual illusion and hallucination to the same category. These are cases of perceptual rather than cognitive impairment. There is distinction in respect of rational justification between the cognition of delusional patients on the one hand and victims of perceptual illusion and hallucination on the other. We obscure this distinction insofar as we maintain that both are examples of blameless irrationality.

To illustrate the point, we can follow Pryor (2001: 117) in contrasting three victims of perceptual hallucination. The first is neither justified nor blameless: he recklessly forms beliefs that are at odds with the contents of experience as a result of carelessness. The second is blameless but not justified: he haplessly forms beliefs that are at odds with the contents of experience as a result of brainwashing. The third is not only blameless but also justified: he forms beliefs in conformity with the contents of experience. The proposal under consideration collapses the distinction between false beliefs that are blameless because they are justified and false beliefs that are blameless despite being unjustified. ${ }^{39}$

We can bolster the argument against Radical Externalism by appealing to the epistemic level-bridging principle that was introduced in section one:

Level Bridging: One has justification to believe that $p$ if and only if one has justification to believe that one has justification to believe that $p$.

\footnotetext{
${ }^{38}$ See Goldman 1988, Williamson 2007, Littlejohn 2012, and Pritchard 2012.

${ }^{39}$ Littlejohn 2012: 44 draws a distinction here between exemptions and excuses, but the distinction relies on a rejection of Level Bridging insofar as one has an excuse only if one has justification for believing falsely that one has justification.
} 
The argument from Level Bridging is as follows. Part of what's bad about the bad case is that one has justification to believe falsely that one is in the good case. If Macbeth suffers a perfect hallucination of a dagger, then he has justification to believe that he sees a dagger, rather than merely hallucinating one. Therefore, he has higher-order justification to believe that he has first-order justification to believe that there is a dagger before him. Given Level Bridging, it follows that he does in fact have justification to believe that there is a dagger before him.

What are the options for blocking the argument? One option is to reject the right-to-left direction of Level Bridging. ${ }^{40}$ On this view, Macbeth lacks first-order justification to believe that there is a dagger before him, but he has second-order justification to believe that he has first-order justification. However, this view has implausible consequences that are familiar from the discussion in section one.

The first implausible consequence is that Macbeth has justification to believe one of the following Moorean conjunctions:

(1) I have justification to believe that there is a dagger before me, but there is no dagger before me; or

(2) I have justification to believe that there is a dagger before me, but it's an open question whether there is a dagger before me.

Intuitively, however, anyone who believes these Moorean conjunctions is thereby unjustified. And this is because no one has justification to believe them.

The second implausible consequence is that Macbeth's belief that there is a dagger before him is unjustified despite being suited to survive a fully justified process of critical reflection. After all, Macbeth has second-order justification to believe that he has first-order justification for the belief in question and so it is suited to survive a process whose aim is to bring one's beliefs into conformity with one's justified higher-order reflections about what one has justification to believe.

40 Notice that this option is hard to reconcile with Factivism: if justification is factive, then second-order justification entails first-order justification. 
But it is implausible that one lacks justification for beliefs that have what it takes to survive a fully justified process of this kind.

The second option is to accept Level Bridging and to block the argument instead by rejecting the premise that Macbeth has second-order justification to believe that he has first-order justification. ${ }^{41}$ On this view, Macbeth has neither firstorder justification to believe that there is a dagger before him nor second-order justification to believe that he has first-order justification. Of course, Macbeth holds these beliefs anyway. But what's bad about the bad case on this view is that Macbeth is psychologically destined to hold beliefs for which he has no justification.

This proposal is consistent with the level-bridging principle stated above. However, it is not easily reconciled with a more general version of the principle whose application is extended from belief to other doxastic attitudes:

Extended Level Bridging: one has justification to adopt some doxastic attitude if and only if one has justification to believe that one has justification to adopt that doxastic attitude.

Let's assume for now (we'll revisit this below) that Macbeth has justification to adopt some doxastic attitude towards the proposition that there is a dagger before him. Radical Externalism implies that he does not have justification to believe it with as much confidence as he does in the good case. Instead, he has justification to either to disbelieve the proposition, to withhold belief, or to believe it with a lower degree of confidence. Given the left-to-right direction of Extended Level Bridging, it follows that he has justification to believe that he has justification to adopt one of these attitudes. That is to say, Macbeth has justification to believe that he is in the bad case. But that is implausible. Part of what is bad about the bad case is that one lacks justification to believe that one is in the bad case.

In response, one might insist that what's bad about the bad case is that one is psychologically incapable of conforming to the standards of epistemic justification.

${ }^{41}$ McDowell 1982, 1995 and Pritchard 2012 combine Factivism with Level Bridging. 
On this view, Macbeth has first-order justification to adopt certain doxastic attitudes, and second-order justification to believe that he has this first-order justification, but he is unable to conform his doxastic attitudes accordingly. But this diagnosis of the bad case has at least two implausible consequences.

The first bad consequence is that perceptual illusion or hallucination involves some rational defect in cognition. As I argued above, however, these are more plausibly regarded as cases of perceptual rather than cognitive impairment. What's bad about the bad case is not that one is cognitively irrational, but rather that cognitive rationality is destined to lead one into ignorance and error about the external world given one's perceptual deficiencies.

The second bad consequence is that a fully rational thinker is always in a position to know when she is in the bad case. But the bad case is plausibly much worse than that: not even a fully rational thinker can know by reflection alone that she is having a perfect hallucination. And being fully rational does not guarantee that one has anything to rely on besides reflection. Even a naïve realist like Martin (2004) concedes that a perfect hallucination is indiscriminable by reflection from veridical perfection in an impersonal sense that abstracts away from the limited cognitive capacities of particular subjects. So the point holds as much for fully rational thinkers as it does for imperfectly rational thinkers like you and me. Any conception of rationality that denies this is hard to countenance.

To avoid these problems, one might experiment with dropping the assumption that one always has justification to adopt some doxastic attitude in the bad case. This is our third and final option. On this view, Macbeth lacks justification to adopt any doxastic attitude towards the proposition that there is a dagger before him. Moreover, he lacks justification to adopt any second-order doxastic attitudes towards propositions about which first-order doxastic attitudes he has justification to hold. These propositions are epistemically inert in the sense that there is no doxastic attitude that he has justification to adopt towards them. As a result, Extended Level Bridging gets no application in the bad case. But this option has its own implausible consequences. 
First, there is no good precedent for the claim that these propositions are epistemically inert. Consider the proposition that the number of books in my office is even. If you lack sufficient justification either to believe it or to disbelieve it, then you have sufficient justification to withhold. In general, withholding is justified by default in the absence of sufficient justification for belief or disbelief. To deny this in the bad case of illusion and hallucination seems ad hoc and unmotivated. ${ }^{42}$

Second, we cannot give a purely negative explanation of what's bad about the bad case in terms of epistemic inertness. Consider the epistemic predicament of someone who is temporarily comatose. They have no first-order justification for adopting doxastic attitudes and they have no second-order justification for believing that they have no first-order justification. But the bad case is not at all like that. Admittedly, there are cognitive differences between these cases, since subjects form beliefs in a case of perceptual illusion and hallucination, but not in a comatose state. However, these cognitive differences fail to explain the relevant epistemic differences. Compare my epistemic predicament in the bad case with that of my temporarily zombified twin. We form the very same beliefs, but our epistemic predicament is nevertheless quite different in ways that cannot be captured in purely negative terms. What's bad about the bad case is not merely that one lacks justification to believe that one is in the bad case. In addition, one has justification to believe falsely that one is in the good case.

Finally, this option repeats the mistake of diagnosing what's bad about the bad case in terms of cognitive irrationality. But now the guarantee of irrationality is not merely "medical" in the way that it was before. On the second option, we are psychologically destined to be irrational in the bad case but our more fully rational selves are not, since there is always some doxastic attitude that we have justification to adopt in the bad case. On the third option, in contrast, there is no way to avoid irrationality in the bad case. Just by virtue of considering the proposition one is guaranteed to adopt some doxastic attitude towards it - even if it is merely the attitude of not yet having made up one's mind. But on this option, there is no such

${ }^{42}$ In section six, I explain why de re propositions don't provide a good precedent. 
doxastic attitude that is justified. So the bad case is an epistemic dilemma in the sense that whatever doxastic attitude one adopts, it is guaranteed to be epistemically unjustified. Whatever you do, you just can't win!

Perhaps the most radical proponents of Radical Externalism will bite the bullet here. What's bad about the bad case, they might say, is that it's an epistemic dilemma in just this sense. My goal here is not so much to persuade them as to persuade a neutral audience that nothing so radical is forced upon us by rejecting internalism in the sense defined in this paper. So the task of the next section is to make the case that Moderate Externalism can avoid these radical commitments.

\section{Moderate Externalism Defended}

In the previous section, I argued that Radical Externalism faces a dilemma. If Level Bridging is rejected, then it is committed to the implausible consequence that Moorean beliefs, along with other beliefs that are unstable under justified reflection, can be fully justified. But if Level Bridging is accepted, then it is committed to an implausible diagnosis of what's bad about the bad case. In this section, I argue that Moderate Externalism avoids this dilemma, since it can be reconciled with Level Bridging without thereby giving an implausible diagnosis of the bad case. If I am right about this, then Level Bridging provides a principled rationale for preferring Moderate Externalism to Radical Externalism.

According to Radical Externalism, there are externalist requirements on epistemic justification in addition to the externalist conditions on mental content. These requirements are satisfied in the good case and violated in the bad case. Radical Externalism therefore entails that there are some propositions that I can entertain in the good case and the bad case alike, although I have justification to believe them only in the good case. So, the following question arises: in the bad case, do I have justification to adopt some other doxastic attitude towards the proposition in question? If so, then Extended Level Bridging comes into effect with awkward results. But if not, then the proposition is epistemically inert for me in the sense that there is no doxastic attitude that I have justification to adopt towards it. In that case, Extended Level Bridging does not come into effect. But the result is an epistemic 
dilemma: once I consider the proposition in question, I cannot avoid adopting any attitude at all, and so I am guaranteed to adopt a doxastic attitude that is unjustified.

According to Moderate Externalism, there are externalist requirements on mental content but no further externalist requirements on epistemic justification. So, for example, one cannot represent de re propositions about an object unless one stands in some appropriate relation - such as a perceptual relation - to the object. But there are no further externalist requirements that one must satisfy in order to have justification to believe de re propositions about the object.

Let's define the really bad case as one that violates externalist requirements for entertaining certain propositions. In the really bad case, I cannot represent those propositions at all. Moreover, my inability to represent these propositions is no reflection of my limited rationality. Therefore, it follows from the Linking Principle (see section three) that these propositions are epistemically inert for me in the sense that there are no doxastic attitudes that I have justification to adopt towards them. Moderate Externalism therefore entails that there are propositions that I have justification to believe in the good case but not the really bad case.

How does Moderate Externalism avoid the dilemma for Radical Externalism? Extended Level Bridging does not come into effect because these propositions are epistemically inert for me in the sense that there is no doxastic attitude that I have justification to adopt towards them. ${ }^{43}$ Moreover, there is no threat of epistemic dilemma since I cannot represent these propositions in the really bad case and so I am unable to violate epistemic standards by adopting some unjustified doxastic attitude. Therefore, both horns of the dilemma are avoided.

To illustrate, take the bad case in which Macbeth hallucinates a dagger and consider the general proposition that there is a dagger before him. Suppose Macbeth does not have justification to adopt the same doxastic attitude that he does in the

${ }^{43}$ Epistemically inert propositions provide counterexamples to an unrestricted version of the J J Principle, which states that one lacks justification to believe a proposition if and only if one has justification to believe that one lacks justification to believe it (see Smithies 2012a). But given plausible assumptions, the Extended Level Bridging principle entails a version of the J J Principle that is restricted to propositions that are not epistemically inert. 
good case. Is there some other doxastic attitude that he has justification to adopt towards this proposition in the bad case? If so, then Extended Level Bridging comes into effect with awkward results. But if not, then the case is an epistemic dilemma, since Macbeth cannot avoid adopting some doxastic attitude towards this proposition as soon as he considers it.

Now consider a de re proposition about some particular object to the effect that it is a dagger. The same dilemma does not arise. Suppose Macbeth does not satisfy the externalist conditions for being able to entertain this proposition and that his inability to do so reflects no rational failing on his part. The Linking Principle entails that there is no doxastic attitude that he has justification to adopt towards this proposition. So Extended Level Bridging does not come into effect. Moreover, there is no epistemic dilemma because Macbeth is unable to adopt doxastic attitudes towards the proposition.

\section{Conclusion}

In this paper, I have argued that perception justifies belief about the external world in virtue of its phenomenal character together with its relations to the external world. But these perceptual relations to the external world impact on the justifying role of perception only by virtue of their impact on its representational content. Moreover, the epistemic level-bridging principle provides a principled rationale for avoiding more radically externalist theories of perceptual justification. ${ }^{44}$

\footnotetext{
${ }^{44}$ I am grateful to audiences at MIT and UT Austin for discussions of this paper and especially to Alex Byrne, Ben Caplan, James Genone, Clayton Littlejohn, Berislav Marusic, and Susanna Siegel for helpful comments on a previous draft.
} 


\section{References}

Audi, R. 2001. An Internalist Theory of Normative Grounds. Philosophical Topics 23: $31-45$.

Bergmann, M. 2005. Defeaters and Higher-Level Requirements. Philosophical Quarterly 55: 419-36.

Bergmann, M. 2006. Justification Without Awareness: A Defense of Epistemic Externalism. New York: Oxford University Press.

Block, N. 1997. On a Confusion About a Function of Consciousness. In N. Block, O. Flanagan and G. Guzeldere, The Nature of Consciousness: Philosophical Debates. Cambridge: MIT Press.

Block, N. 2003. Mental Paint. In M. Hahn and B. Ramberg, Reflections and Replies: Essays on the Philosophy of Tyler Burge. Cambridge: MIT Press.

BonJour, L. 1985. The Structure of Empirical Knowledge. Cambridge: Harvard University Press.

Brewer, B. 2006. Perception and Content. European Journal of Philosophy 14.2: 16581.

Burge, T. 1979. Individualism and the Mental. Midwest Studies in Philosophy 4.1: 73121.

Burge, T. 2003. Perceptual Entitlement. Philosophy and Phenomenological Research 67.3: 503-48.

Byrne, A. 2001. Intentionalism Defended. Philosophical Review 110 (2): 199-240.

Campbell, J. 2002. Reference and Consciousness. Oxford: Oxford University Press.

Chalmers, D. 2002. The Components of Content. In D. Chalmers, Philosophy of Mind: Classical and Contemporary Readings. New York: Oxford University Press.

Chalmers, D. 2004. The Representational Character of Experience. In B. Leiter, The Future for Philosophy. New York: Oxford University Press.

Cohen, S. 1984. Justification and Truth. Philosophical Studies 46: 279-295.

Conee, E. \& R. Feldman. 2004. Evidentialism: Essays in Epistemology. New York: Oxford University Press.

Conee, E. 2007. "Externally Enhanced Internalism." In S. Goldberg, Internalism and Externalism in Semantics and Epistemology. Oxford: Oxford University Press. 
Davies, M. 1997. Externalism and Experience. In N. Block, O. Flanagan, and G. Guzeldere, The Nature of Consciousness: Philosophical Debates. Cambridge: MIT Press.

Evans, G. 1982. The Varieties of Reference. Oxford: Clarendon Press.

Farkas, K. 2008. Phenomenal Intentionality Without Compromise. Monist 91.2: 27393.

Firth, R. 1978. Are Epistemic Concepts Reducible to Ethical Concepts? In A. Goldman and J. Kim, Values and Morals. Dordrecht: Kluwer.

Fish, W. 2008. Disjunctivism, Indistinguishability, and the Nature of Hallucination. In A. Haddock and F. Macpherson, Disjunctivism: Perception, Action, Knowledge. Oxford: Oxford University Press.

Goldman, A. 1979. What is Justified Belief? In G. Pappas, Justification and Knowledge. Dordrecht: Reidel.

Goldman, A. 1988. Strong and Weak Justification. Philosophical Perspectives 2: 51-69.

Harman, G. 1990. The Intrinsic Quality of Experience. Philosophical Perspectives 4: 31-52.

Horgan, T. and Tienson, J. 2002. The Intentionality of Phenomenology and the Phenomenology of Intentionality. In D. Chalmers, Philosophy of Mind: Classical and Contemporary Readings. New York: Oxford University Press.

Huemer, M. 2001. Skepticism and the Veil of Perception. Rowman and Littlefield.

Johnston, M. 2004. The Obscure Object of Hallucination. Philosophical Studies 120: 113-183.

Kelly, T. 2013. Evidence Can Be Permissive. In M. Steup, J. Turri, and E. Sosa, Contemporary Debates in Epistemology. Oxford: Blackwell.

Kripke, S. 1979. A Puzzle about Belief. In A. Margalit, Meaning and Use. Dordrecht: Reidel.

Littlejohn, C. 2012. Justification and the Truth-Connection. Cambridge: Cambridge University Press.

Littlejohn, C. 2013. A Note Concerning Justification and Access. Episteme 10.4: 369386. 
Lyons, J. 2009. Perception and Basic Beliefs: Zombies, Modules, and the Problem of the External World. New York: Oxford University Press.

Martin, M. 2002. Particular Thoughts and Singular Thought. In A. O'Hear, Logic, Thought, and Language. Cambridge: Cambridge University Press.

Martin, M. 2004. The Limits of Self-Awareness. Philosophical Studies 120: 37-89.

McDowell, J. 1982. Criteria, Defeasibility, and Knowledge. Proceedings of the British Academy 68: 455-79.

McDowell, J. 1995. Knowledge and the Internal. Philosophy and Phenomenological Research 55.5: 877-93.

McGinn, C. 1988. Consciousness and Content. Proceedings of the British Academy 74: 219-39.

McGrath, M. 2013. Phenomenal Conservatism and Cognitive Penetration. In C. Tucker, Seemings and Justification. New York: Oxford University Press.

Peacocke, C. 1983. Sense and Content: Experience, Thought, and Their Relations. Oxford: Oxford University Press.

Peacocke, C. 1993. Externalist Explanation. Proceedings of the Aristotelian Society 67: 203-30.

Pritchard, D. 2012. Epistemological Disjunctivism. Oxford: Oxford University Press.

Pryor, J. 2000. The Skeptic and the Dogmatist. Noûs 34.4: 517-49.

Pryor, J. 2001. Highlights of Recent Epistemology. British Journal for the Philosophy of Science 52: 95-124.

Putnam, H. 1975. The Meaning of 'Meaning'. Philosophical Papers, Volume II: Mind, Language and Reality. Cambridge: Cambridge University Press.

Roessler, J. 2009. Perceptual Experience and Perceptual Knowledge. Mind 118: 1013-41.

Schellenberg, S. 2013. Experience and Evidence. Mind 122: 699-747.

Siegel, S. 2004. Indiscriminability and the Phenomenal. Philosophical Studies 120: 90-112.

Siegel, S. 2011. The Contents of Visual Experience. New York: Oxford University Press. Siewert, C. 1998. The Significance of Consciousness. Princeton: Princeton University Press. 
Silins, N. 2011. Seeing Through 'The Veil of Perception'. Mind 120: 329-67.

Smithies, D. 2006. Rationality and the Subject's Point of View. Ph.D. thesis, New York University.

Smithies, D. 2012a. Moore's Paradox and the Accessibility of Justification. Philosophy and Phenomenological Research 85.2: 273-300.

Smithies, D. 2012b. A Simple Theory of Introspection. In D. Smithies and D. Stoljar, Introspection and Consciousness. New York: Oxford University Press.

Smithies, D. 2012c. Mentalism and Epistemic Transparency. Australasian Journal of Philosophy 90.4: 723-41.

Smithies, D. 2014. The Phenomenal Basis of Epistemic Justification. In J. Kallestrup and M. Sprevak, New Waves in Philosophy of Mind. London: Routledge.

Smithies, D. 2015. Why Justification Matters. In D. Henderson and J. Greco, Epistemic Evaluation: Point and Purpose in Epistemology. New York: Oxford University Press.

Sosa, E. 1991. Knowledge in Perspective: Selected Essays in Epistemology. Cambridge: Cambridge University Press.

Strawson, P. 1959. Individuals: An Essay in Descriptive Metaphysics. London: Routledge.

Tye, M. 1995. Ten Problems of Consciousness. Cambridge: MIT Press.

Weiskrantz, L. 1997. Consciousness Lost and Found: A Neuropsychological Exploration. New York: Oxford University Press.

White, R. 2013. Evidence Cannot Be Permissive. In M. Steup, J. Turri, and E. Sosa, Contemporary Debates in Epistemology. Oxford: Blackwell.

Williamson, T. 2000. Knowledge and Its Limits. Oxford University Press.

Williamson, T. 2007. On Being Justified in One's Head. In M. Timmons, J. Greco, and A. Mele, Rationality and the Good. New York: Oxford University Press. Yablo, S. 1997. Wide Causation. Philosophical Perspectives 11: 251-81. 